Article

\title{
Protein Identification of Venoms of the African Spitting Cobras, Naja mossambica and Naja nigricincta nigricincta
}

\author{
Ottilie Katali $^{1}{ }^{1}$, Loide Shipingana ${ }^{1}\left(\mathbb{D}\right.$, Peter Nyarangó $^{1}{ }^{1}$, Mirva Pääkkönen ${ }^{2}$, \\ Erastus Haindongo ${ }^{1} \mathbb{D}$, Timothy Rennie ${ }^{1}{ }^{(\mathbb{D}}$, Peter James ${ }^{2}$, John Eriksson ${ }^{2,3}$ and \\ Christian John Hunter $1, *$ (D) \\ 1 Faculty of Health Sciences, University of Namibia, Windhoek 9000, Namibia; ottiliekatali@gmail.com (O.K.); \\ loideshipingana@gmail.com (L.S.); pnyarango@gmail.com (P.N.); ehaindongo@unam.na (E.H.); \\ trennie@unam.na (T.R.) \\ 2 Turku Bioscience Centre, University of Turku and Åbo Akademi University, FI-20520 Turku, Finland; \\ mirva.paakkonen@bioscience.fi (M.P.); peter.james@immun.lth.se (P.J.); John.Eriksson@abo.fi (J.E.) \\ 3 Cell Biology, Faculty of Science and Technology, Åbo Akademi University, FI-20520 Turku, Finland \\ * Correspondence: chunter@unam.na
}

Received: 16 June 2020; Accepted: 27 July 2020; Published: 14 August 2020

check for updates

\begin{abstract}
Cobra snakes, including Naja mossambica and Naja nigricincta nigricincta, are one of the major groups of snakes responsible for snakebites in southern Africa, producing significant cytotoxicity and tissue damage. The venom of N. mossambica has been briefly characterised, but that of N. n. nigricincta is not reported. The current study identifies the venom proteins of N. mossambica and N. n. nigricincta. This is achieved using sodium dodecyl sulphate (SDS)-polyacrylamide gel eletrophroresis (PAGE), followed by high-performance liquid chromatography-tandem mass spectrometry (HPLC-MS/MS). Most of the proteins were less than $17 \mathrm{kDa}$ in both snakes. N. mossambica was found to have 75 proteins in total (from 16 protein families), whereas N.n. nigricincta had 73 (from 16 protein families). Of these identified proteins, 57 were common in both snakes. The proteins identified belonged to various families, including the three-finger toxins (3FTx), Cysteine-rich secretory proteins (CRiSP), Phospholipase A2 (PLA 2 ) and Venom metalloproteinase M12B (SVMP). The current study contributes to the profile knowledge of snake venom compositions, which is of fundamental value in understanding the proteins that play a major role in envenomation.
\end{abstract}

Keywords: African spitting Cobras; Naja mossambica; Naja nigricincta nigricincta; snake venom; snakebites; antivenin

Key Contribution: This is the first study on the venom profile of N. n. nigricincta.

\section{Introduction}

Snakebites are a major cause of morbidity and mortality in Africa, Asia and Latin America, [1,2], yet, a neglected tropical disease-mostly affecting remote and rural tropical regions [3-5]. The burden of snakebites has been estimated at 1.2 to 5.5 million per year worldwide [6], with about 400,000 victims ending up with permanent disabilities [2,7]. In Namibia, Southern Africa, 721 snakebites were recorded over the course of 12 months (August 2015 to July 2016) in the main referral hospital in the capital city, Windhoek [8]. These snakebites were caused by different snakes, including spitting cobra snakes, and a large proportion of the people bitten were children under the age of six-years-old-and many of these children suffered long-term disability [8]. Medically important Namibian spitting cobras include the Naja mossambica (Mozambique spitting cobra,) N. nigricollis (black-necked spitting cobra) 
and the N. nigricincta nigricincta (western barred spitting cobra or zebra snake), and its subspecies of N. nigricincta woodi (black spitting cobra) [9-12] (Figure 1). N. n. nigricincta is the most problematic.

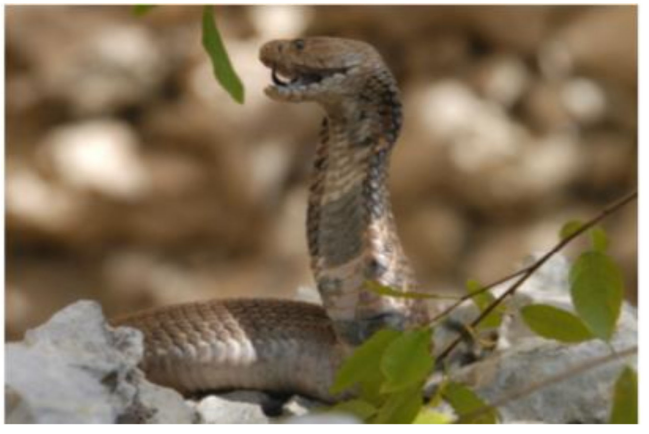

(a)

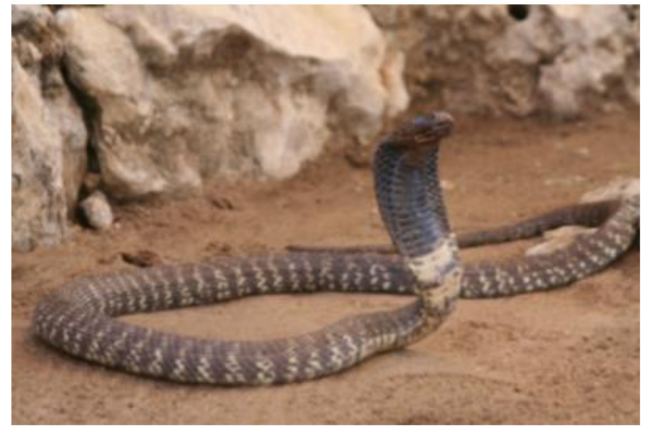

(b)

Figure 1. The figure shows two common spitting cobras in Namibia under study: (a) Naja mossambica (Mozambique spitting cobra); (b) Naja nigricincta nigricincta (western barred spitting cobra or zebra snake). Photos courtesy of the Living Desert Snake Park (Angela Curtis and Stretch Cowbrink).

The limitation of medical facilities in rural areas makes it a challenge for snakebite victims who are often several hours away from the nearest health centre, and may not be equipped to effectively manage these medical emergencies $[13,14]$. Snakebite management is challenging as the identities of the snakes is not always known [15], and there is incomplete knowledge about best treatment practices. The choice of treatment in Namibia is usually limited to (1) supportive care, (2) a monovalent antivenin for confirmed Boomslang bites and (3) a polyvalent antivenin from the South African Institute for Medical Research (SAIMR) for any other snakebites [16].

The efficacy of the antivenins is highly dependent on the snake venom from which it is developed [17]. The SAIMR polyvalent antivenin is based on the venoms from ten snakes of viperine and elapids families (South African Vaccine Producers (PTY) Ltd., Gauteng, South Africa), and therefore, thought to be effective against those respective snakes [18-21]. However, the N. n. nigricincta venom is not included the production of this polyvalent. Locally, it has been observed that the polyvalent seem ineffective against the $N$. n. nigricincta, of which some local clinicians indicated that aggressive debridement is the cornerstone of snakebite management.

In general, envenomations from these snakes cause severe cytotoxicity, necrosis, haemorrhage, anticoagulant and thrombolytic injuries, which may result in death [19]. These potent characteristics of envenomations are due to the venom compositions of the snakes. In general, the lyophilised venom compositions of numerous snakes are made up of $80 \%$ to $100 \%$ proteins and other non-protein components, including carbohydrates, lipids, amines, and inorganic salts [22]. Table 1 summarises the common protein families in various snake venoms and their functions. In elapids, the venom compositions mainly consist of two protein families: (1) Three-finger toxins (3TFxs), which are in highest abundance in most species and (2) the phospholipase A2s (PLA2s), which are the second most abundant [22]. The lyophilised venom composition of the N. mossambica from Tanzania has been characterised and is made up of $99 \%$ proteins, where $\sim 69 \%$ are $3 \mathrm{TFxs}, \sim 27 \%$ are PLA2s, and $\sim 3 \%$ are the snake venom serine proteases (SVSPs) [23]. The other $\sim 1 \%$ of the venom is made up of endonuclease and unknown substances [23]. To our knowledge, the venom composition N. n. nigricincta has not been characterised. However, in animals, the N.n. nigricincta venom has been reported to possess haemorrhagic, necrotic, procoagulant and thrombolytic activities [13]. The present study aimed to profile the venom composition of $N$. mossambica and N. n. nigricincta from Namibia. 
Table 1. This table summarises some of the common protein families found in various snake venoms, including elapids.

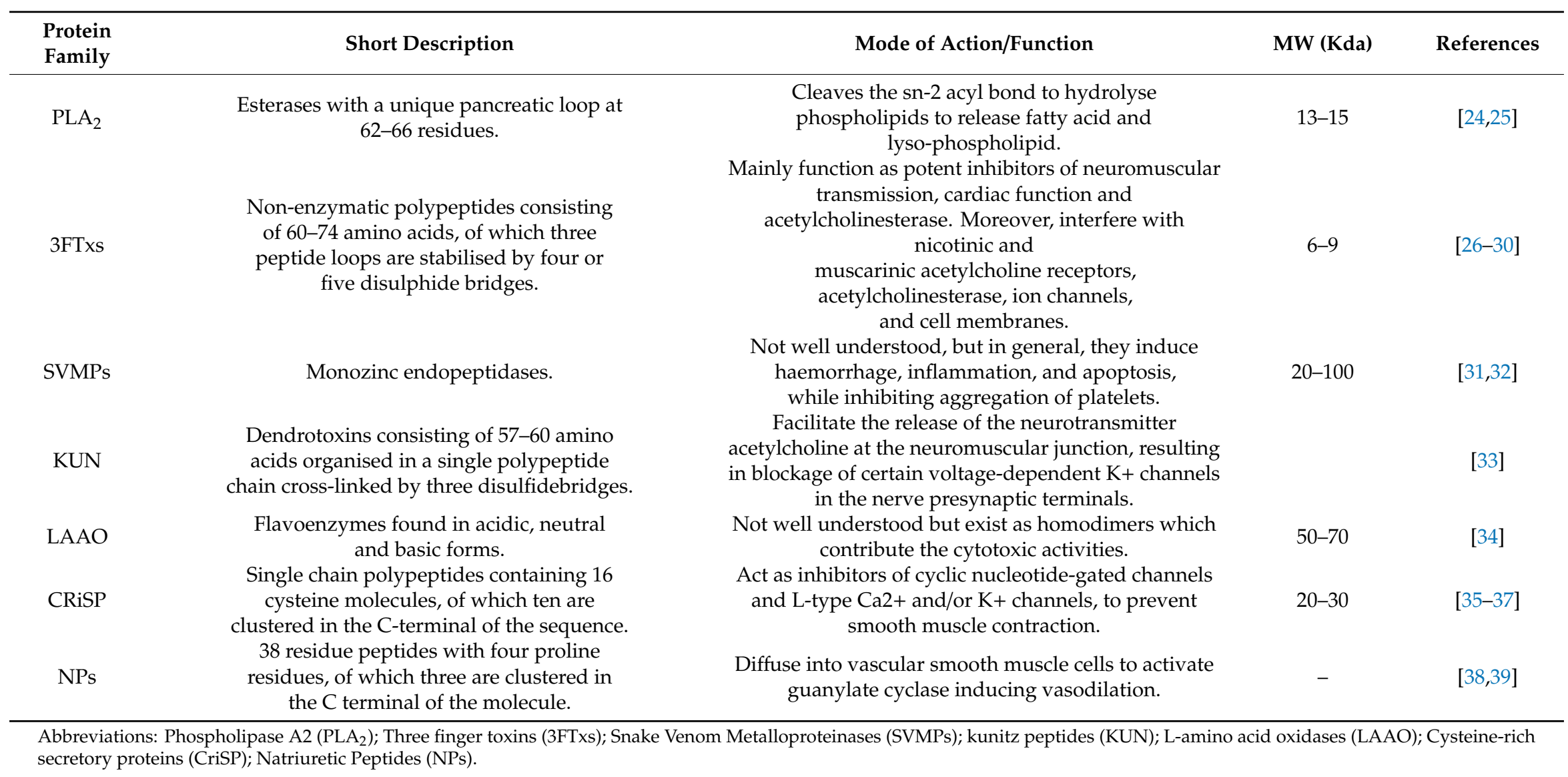




\section{Results}

The sodium dodecyl sulphate (SDS)-polyacrylamide gel eletrophroresis (PAGE) results indicated that most of the proteins were less than $17 \mathrm{kDa}$ in both N. mossambica and N.n. nigricincta, as shown in cluster one (Figure 2).
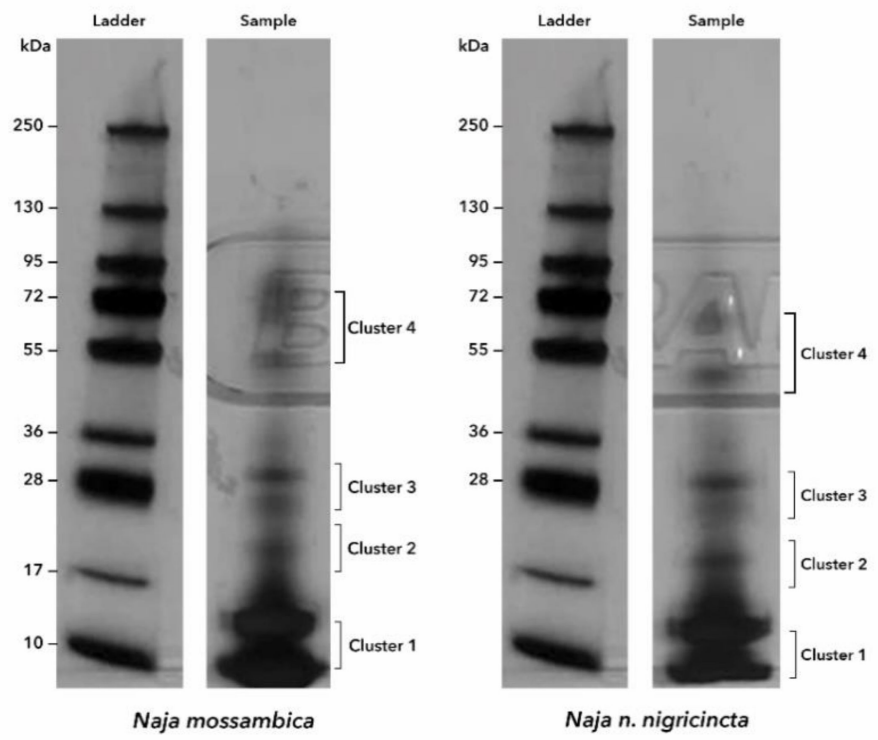

Figure 2. This figure shows the SDS-PAGE of protein separation of the venoms of N. mossambica and N.n. nigricincta. The molecular weight marker (in $\mathrm{kDa}$ ) is on the left of each venom sample for N. mossambica and N. n. nigricincta. The proteins were run in duplicates at $200 \mathrm{~V}$ for 40 min until the dye front reached the end of the six to $16 \%$ precast gel. The gels were silver-stained and digested with trypsin and analysed with HPLC-MS/MS.

The high-performance liquid chromatography-tandem mass spectrometry (HPLC-MS/MS) raw data files were searched with Proteome Discoverer 2.2 software (Thermo Fisher Scientific, Waltham, MA, USA). Proteins which were identified with only one peptide were filtered out from the results. Only four and three proteins were identified when the N. mossambica and N. n. nigricincta venom samples were analysed without digestion, respectively. A total of 32 and 22 proteins, from N. mossambica and N. n. nigricincta respectively, were identified with in-solution digestion. However, the vast majority of the proteins were identified from in-gel digested samples (see Table 2). When all approaches were merged, a total of 75 and 73 proteins were identified for N. mossambica and N. n. nigricincta which belong to 16 families per snake. Of these, 57 were common to both snakes (see Figure 3 and Table 3). The mass of the proteins identified ranged from Individual 2.7 to 184.6 and 3.4 to $184.6 \mathrm{kDa}$ for N. mossambica and N.n. nigricincta respectively (See Tables S1-S3). The quantity of the identified proteins was not determined.

Table 2. This table shows the number of proteins identified per approaches for the venoms of Naja mossambica and Naja nigricincta. nigricincta.

\begin{tabular}{ccc}
\hline \multirow{2}{*}{ Method Approach } & \multicolumn{2}{c}{ Number of Proteins Per Species } \\
\cline { 2 - 3 } & $\begin{array}{c}\text { N. mossambica } \\
\mathbf{n}(\mathbf{\%})\end{array}$ & $\begin{array}{c}\text { N. } \boldsymbol{n} \text {. } \text { nigricintca } \\
\mathbf{n}(\mathbf{\%})\end{array}$ \\
\hline In-gel digestion (Silver-stained) & $71(94.7)$ & $68(93.2)$ \\
In-gel digestion (Not stained) & $54(72.0)$ & $58(79.5)$ \\
In solution digestion & $32(42.7)$ & $22(30.1)$ \\
No digestion & $4(5.3)$ & $3(4.1)$ \\
\hline
\end{tabular}




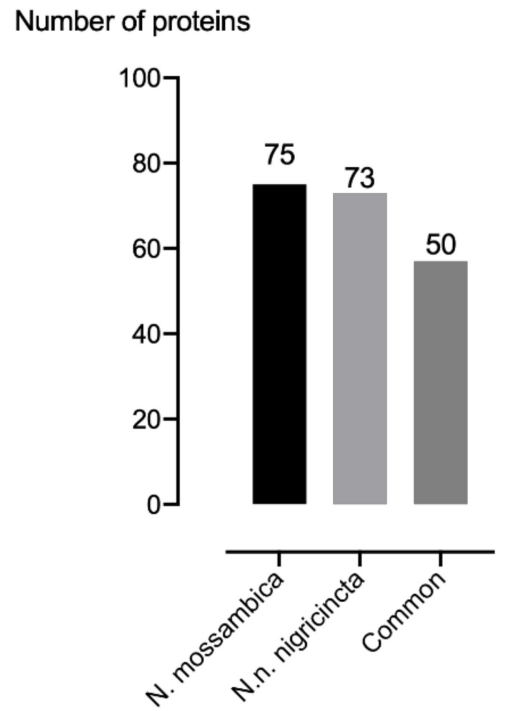

Figure 3. This figure shows the protein counts for N. mossambica and N.n. ningricincta venom and those common to both snakes.

Table 3. This table summarises the number of proteins identified for each protein family from the venoms of N. mossambica and N. n. nigricincta.

\begin{tabular}{cccc}
\hline & & Number of Proteins & \\
\cline { 2 - 4 } Protein Family & N. mossambica & N. n. nigricintca & $\begin{array}{c}\text { Common to } \\
\text { Both Snakes }\end{array}$ \\
\cline { 2 - 4 } 5'-nucleotidase $_{\text {Cathelicidin }}$ & 0 & 1 & 1 \\
Cystatin & 2 & 0 & 0 \\
Cysteine-rich secretory protein (CRiSP) & 1 & 0 & 1 \\
Flavin monoamine oxidase & 1 & 3 & 6 \\
Glycosyl hydrolase 56 & 1 & 1 & 4 \\
Nerve growth factor (NGF-Beta) & 0 & 2 & 0 \\
Nucleotide & 0 & 1 & 3 \\
pyrophosphate/phosphodiesterase & 0 & 0 & 1 \\
Ohanin/vespryn & 0 & 0 & 1 \\
Peptidase S1 & 0 & 0 & 1 \\
Peroxiredoxin & 0 & 1 & 0 \\
Phospholipase A2 (PLA2) & 1 & 1 & 6 \\
Phospholipase B & 0 & 0 & 2 \\
Three finger toxins (3FTx) & 10 & 5 & 20 \\
True venom lectin & 0 & 0 & 1 \\
Venom complement C3 homolog & 0 & 0 & 3 \\
Venom Kunitz-type family & 1 & 0 & 0 \\
Venom metalloproteinase M12B (SVMP) & 1 & 1 & 7 \\
Total & 18 & 16 & 57 \\
\hline
\end{tabular}

The number of proteins identified by four different approaches was pooled together to classify them into their respective families for $N$. mossambica and N. n. nigricincta venoms.

Three-finger toxins (3FTx) seemed to be the most abundant protein family, with 30 and 25 identified in N. mossambica and N. n. nigricincta, respectively. Various proteins were identified from the following families: Cysteine-rich secretory proteins (CRiSP), Phospholipase A2 ( $\left.\mathrm{PLA}_{2}\right)$ and Venom metalloproteinase M12B (SVMP). Unique protein families identified in N. mossambica included cathelicidin and venom kunitz-type. On the other hand, glycosyl hydrolase 56 and peroxiredoxin families were only found in N. n. nigricincta (See Table 3 and Table S1). 
Prior to HPLC-MS/MS analysis, proteins were either subjected to silver stain in-gel digestion, (ii) no stain in-gel digestion, (iii) in-solution digestion, and (iv) no digestion. The percentage is relative to the total number of proteins from all approaches merged for N. mossambica (75 proteins) and N. n. nigricincta (73 proteins).

\section{Discussion}

The venoms of the cobra snakes N. mossambica and N.n. nigricincta are known to possess cytotoxic activity to their victims $[13,19]-N$. nigricincta is also reported to possess haemorrhagic, anticoagulant, and thrombolyt activity in animals [13]. The present study aimed to characterise the venoms of these cobra snakes in order to identify the specific proteins present. We carried out a bottom-up approach, however, acetonitrile precipitated proteins were analysed without digestion, in order to identify the protein complexity of the venoms of N. mossambica and N. n. Nigricincta. The protein complexity of the venoms of N. mossambica from Tanzania was previously characterised [23], while that of N. n. nigricincta, to our knowledge, is reported for the first time in the present study.

In the current study, it is demonstrated that various proteins known to be responsible for pathological effects reported in various snake envenomation are also present in the two snakes, N. mossambica and N. n. nigricincta [22]. Moreover, the venom of the two snakes share more than 50\% of the identified proteins. The majority of these proteins had a molecular mass of about $17 \mathrm{kDa}$ and less (see Figure 2). Most proteins seemed to belong to the 3FTx family followed by CRiSP, SVMP and $\mathrm{PLA}_{2}$ and a couple from other families (see Table 3 and Table S1). However, this is the first study on the venom profile of $N$. n. nigricincta, similar protein families were reported by Petras et al. [23] for the venom of $N$. mossambica with the exemption of endonuclease family, of which our current study did not record. In addition, 12 more other protein families were identified for N. mossambica in the present study (Table 3). The variation among studies in protein identification may be due to the difference in the geographical location of the snakes. Moreover, Petras et al. [23] identified proteins from the Nawaprin family in the venom of N. nigricollis from Nigeria, Togo, and Cameroon, but not in that of the Tanzanian, which again may be due to different geographical locations.

Due to the complexity of snake venom proteins, only a fraction of proteins and peptides can be identified in a single run of LC-MS/MS [40,41]. Hence, the experimentation of such complex samples is very critical, and the differences in techniques may result in variations among the analysis. In order to produce a high-throughput protein identification. The current study used four sample preparation methods incorporated with HPLC-MS/MS analysis (see Table 2), of which each method gave only a fraction of the total proteins identified. For instance, in N. n. nigricincta, the fragment cysteine-rich venom protein mossambin (accession, P0DL16) and cytotoxin Vc-5 (accession, Q9PS34) were only identified with the in-solution digestion approach. Whereas, basic phospholipase A2 nigexine (accession, P14556) was only identified with the silver-stained in-gel digestion method (See Table S4).

Furthermore, the precursor ion exclusion list consisting of all identified proteins in preceding runs was used to analyse HPLC-MS/MS analysis output for the no stain in-gel digestion method. This method eliminated redundant proteins of high abundance, allowing identification of new and unique proteins that were missed in the first run. For example, c-type lectin galactose-binding isoform (accession, D2YVI2) and cytotoxin SP13b (accession, P60306) were identified only after the subjection of the exclusion list. Thus, the use of different sample preparation methods and replicated runs, coupled with the exclusion list, improved the comprehensiveness of protein analysis (See Table S3).

There have been several monovalent and polyvalent antivenins used for cross neutralisation of snake envenomations [18,42]. The efficiency of the antivenin is highly dependent on the snake venom, on which it is based [17]. The South African Institute for Medical Research (SAIMR) polyvalent antivenin is the most commonly used in Africa [16,18], which has been used for cross neutralisation of the venom for more than 35 years [19]. In Namibia, most N.n. nigricincta envenomation incidences treated with this antivenin have been recorded to undergo radical excision around the site of the snakebite [43]. The treatment of these envenomations is done using the SAIMR polyvalent [16], 
of which N.n. nigricincta is not considered in its preparation [18,43]. Another example of ineffective antivenin has been reported by Sintiprungrat et al. [13], where the antivenin produced against the Indian N. naja was less effective against the Sri Lankan N. naja. The composition of the venom from these species has geographical intra-specific variations [17].

\section{Conclusions}

In conclusion, even though the composition of the proteins was not quantified, the venoms of the two cobra snakes N. mossambica and N.n. nigricincta have been successfully profiled, revealing a vast spectrum of proteins. The current study proposes further characterisations of these venoms for quantification to better understand these proteins, their toxicity and even therapeutic candidacy.

\section{Materials and Methods}

\subsection{Snake Venom Samples}

The venoms were milked from each adult N. mossambica and N.n. nigricincta and were lyophilised, yielding 95.3 and $129.2 \mathrm{mg}$, respectively [13]. These crude venom samples were stored at $-20{ }^{\circ} \mathrm{C}$ until experimentation. The study was approved by National Commission on Research Science and Technology of Namibia through the University of Namibia (Certificate: RCIV00022018) and the exportation of samples to the Turku Bioscience Centre, Finland was permitted by the Namibian Ministry of Environment and Tourism (Permit: 118430).

\subsection{Venom Protein Separation by SDS-PAGE and In-Gel Digestion}

Crude venoms were dissolved in Laemmli buffer (one mg in $200 \mu \mathrm{L}$ ). From these samples, $50 \mu \mathrm{L}$ were then separated by SDS-PAGE in six to $16 \%$ precast gel (Bio-Rad, Hercules, CA, USA). This was run at $200 \mathrm{~V}$ for $40 \mathrm{~min}$ until the dye front reached the end of the gel, was silver-stained, and cut into 16 pieces for a lane. Another gel was run under similar conditions except it was only allowed to run for $5 \mathrm{~cm}$ into the resolving gel and was not stained. These gels were digested using trypsin enzyme as described previously [44-46].

\subsection{Acetonitrile Precipitation and In-Solution Digestion}

Proteins $(>10 \mathrm{kDa})$ were removed from the venom samples by acetonitrile precipitation. One $\mathrm{mg}$ of a dry venom sample was dissolved in $200 \mu \mathrm{l} 80 \%$ acetonitrile, and then centrifuged for six minutes at 5000 relative centrifugal force ( $\mathrm{rff}$ ). The supernatants containing peptides and small proteins were dried in SpeedVac. Dried supernatants were dissolved in $0.1 \%$ formic acid, and protein concentrations were determined with NanoDrop. In order to be able to detect also the possible small proteins and natural peptides in the venom samples, and not only tryptic peptides, each supernatant sample was divided into two portions. One portion of each sample was run with HPLC-MS/MS without carrying out digestion before the analysis. In order to analyse the tryptic peptides, the second portion of each sample was in-solution digested by reconstituting the sample to six $\mathrm{M}$ urea in $50 \mathrm{mM}$ Tris- $\mathrm{HCl}$ (urea was used to denaturate the protein structure), reduced with $200 \mathrm{mM}$ 1,4-dithiotreitol, alkylated using $200 \mathrm{mM}$ iodoacetamide, and digested with trypsin (1:30 trypsin:substrate ratio) overnight at $37^{\circ} \mathrm{C}$. After digestion proteins were desalted using Sep-Pak C18 cartridges (Waters Corporation, Milford, MA, USA) and dried in SpeedVac.

\subsection{LC-ESI-MS/MS Analysis}

The tryptic peptide samples were then re-suspended into $0.1 \%$ formic acid so that a theoretical protein concentration was $3 \mu \mathrm{g} / \mu \mathrm{L}$ for each sample. The samples were further diluted in a ratio 1:15, so that theoretically $200 \mathrm{ng}$ of each sample was injected into a nanoflow HPLC system (Easy-nLC1200, Thermo Fisher Scientific, Bremen, Germany) coupled to the Q Exactive HF (Thermo Fisher Scientific, in-gel digested samples) or to the $Q$ Exactive mass spectrometer (Thermo Fisher Scientific, in-solution 
digested samples and concentrated gel samples) equipped with a nano-electrospray ionisation source. Peptides were first loaded on a trapping column and subsequently separated inline on $15 \mathrm{~cm} \mathrm{C18 \textrm {column }}$ $(75 \mu \mathrm{m} \times 15$ cm, ReproSil-Pur $5 \mu \mathrm{m} 200$ Ã C18-AQ, Dr. Maisch HPLC GmbH, Ammerbuch-Entringen, Germany); the mobile phase consisted of water with $0.1 \%$ formic acid (solvent $\mathrm{A}$ ) and acetonitrile/water $(80: 20(v / v))$ with $0.1 \%$ formic acid (solvent B); the active gradient lengths used depended on the complexity of the sample ranging between 10 to $120 \mathrm{~min}$. The flow rate was set at $300 \mathrm{~nL} / \mathrm{min}$. Concentrated gel samples were first run using data-dependent acquisition method. In order to increase the number of identifications, precursor ions of identified peptides were added to mass exclusion list, and samples were re-run with mass spectrometer. This was repeated once. When creating the exclusion lists, precursor mass tolerance was set to $\pm 8 \mathrm{ppm}$, fragment mass tolerance to at $\pm 0.02 \mathrm{Da}$, maximum missed cleavages was set to two. Only precursors with high or medium confidence were selected for the exclusion lists. A significance threshold of $p<0.05$ was used. No replicate runs were made on other samples.

\subsection{Data Analysis}

For data analysis, raw data were processed using Proteome Discoverer 2.2 (Thermo Fisher Scientific). The software was connected to an in-house server running the Mascot 2.6.1 software (Matrix Science). Data were searched against a custom-made venom database and target decoy database. The venom database was downloaded from UniProt (28.6.2018) and contained 6328 protein sequences from 655 different venomous species (See Table S4). In Proteome Discoverer MS/MS peptide mass tolerance was set at $\pm 8 \mathrm{ppm}$, fragment mass tolerance at $\pm 0.02 \mathrm{Da}$ and the maximum missed cleavages was set to two. Carbamidomethyl (C) was chosen as a static modification. Oxidation (M) and acetyl (protein N-terminus) were chosen as dynamic modifications. Trypsin was selected as enzyme for digested samples. The non-digested samples were searched with 'none' selected as the enzyme. The Fixed Value, PSM validator node, was used to assign confidence to PSMs based on fixed score threshold of 0.05 . Only protein with high or medium confidence are listed in this paper, and all identifications are based on at least two peptides per protein. A significance threshold of $p<0.05$ was used. The processed data were exported as Microsoft Excel files and proteins which were identified with only one peptide were filtered out from the results and those that did not match the database were not identified. The mass spectrometry proteomics data have been deposited to the ProteomeXchange Consortium via the PRIDE [47] partner repository with the dataset identifier PXD020411.

Supplementary Materials: The following are available online at http://www.mdpi.com/2072-6651/12/8/520/s1, Table S1: Proteins identified from the venoms of N. n. nigricincta and N. mossambica, Table S2: Total number of proteins found in N. mossambica, Table S3: Total number of proteins found in N. n. nigricincta, Table S4: List of species in the custom-made venom database.

Author Contributions: Conceptualisation, C.J.H., J.E., T.R., P.J. and P.N.; methodology, P.J., M.P., O.K., L.S. and E.H.; software, P.J., M.P., O.K., L.S. and E.H.; validation, P.J. and M.P.; formal analysis, P.J., M.P., O.K., L.S. and E.H.; investigation, P.J., M.P., O.K., L.S. and E.H.; resources, C.J.H., J.E., T.R. and P.N.; data curation, P.J., M.P., O.K., L.S. and E.H.; writing-original draft preparation, M.P., O.K., L.N.N.S. and E.H.; writing-review and editing, C.J.H., J.E., T.R., P.N., P.J., M.P., O.K., L.S. and E.H.; supervision, C.J.H., J.E., T.R., P.J. and P.N.; project administration, C.J.H., J.E., T.R., P.N., P.J., M.P., O.K., L.S. and E.H.; funding acquisition, C.J.H., J.E. and P.N. All authors have read and agreed to the published version of the manuscript.

Funding: This research was funded by Centre for International Mobility in Finland (CIMO), Finnish Science, Technology and Innovation Cooperation between Europe, Africa, Asia and the LAC Region: FinCEAL Plus Continuation (FinCEAL Plus) and Southern African-Nordic Centre (SANORD) and the Article Processing Charge (APC) was funded by University of Namibia (UNAM).

Acknowledgments: The venom samples of the cobra snakes, N. mossambica and N. n. nigricincta were supplied by Erick Kandiwa, from School of Veterinary Medicine, Faculty of Agriculture and Natural Resources, Neudamm Campus, University of Namibia. The experiments were performed at the Turku Proteomics Facility, University of Turku and Åbo Akademi University, which is supported by Biocenter Finland. The traveling and living costs for O.K, L.S and E.H during experimentations in Finland were supported by the University of Namibia and University of Turku. Special thanks to Stretch Cowbrink and Angela Curtis of the 'Living Desert Snake Park' in Swakopmund Namibia for the photographs of the spitting cobras. 
Conflicts of Interest: The authors declare no conflict of interest.

\section{References}

1. De Silva, J.; Kasturiratne, A.; Pathmeswaran, A.; Lalloo, D.G. Snakebite: The true disease burden has yet to be determined. Ceylon Med. J. 2013, 58, 93. [CrossRef] [PubMed]

2. WHO. Snakebite Envenoming. 2019. Available online: https://www.who.int/en/news-room/fact-sheets/ detail/snakebite-envenoming (accessed on 7 August 2019).

3. Habib, A.G.; Kuznik, A.; Hamza, M.; Abdullahi, M.I.; Chedi, B.A.; Chippaux, J.-P.; Warrell, D.A. Snakebite is Under Appreciated: Appraisal of Burden from West Africa. PLoS Negl. Trop. Dis. 2015, 9, e0004088. [CrossRef] [PubMed]

4. Chippaux, J.-P. Snakebite envenomation turns again into a neglected tropical disease! J. Venom. Anim. Toxins Incl. Trop. Dis. 2017, 23, 1-2. [CrossRef] [PubMed]

5. $\quad$ Longbottom, J.; Shearer, F.M.; Devine, M.; Alcoba, G.; Chappuis, F.; Weiss, D.J.; Ray, S.E.; Ray, N.; Warrell, D.A.; De Castañeda, R.R.; et al. Vulnerability to snakebite envenoming: A global mapping of hotspots. Lancet 2018, 392, 673-684. [CrossRef]

6. Kasturiratne, A.; Wickremasinghe, A.R.; De Silva, N.; Gunawardena, N.K.; Pathmeswaran, A.; Premaratna, R.; Savioli, L.; Lalloo, D.G.; De Silva, H.J. The Global Burden of Snakebite: A Literature Analysis and Modelling Based on Regional Estimates of Envenoming and Deaths. PLoS Med. 2008, 5, e218. [CrossRef]

7. Williams, D.J.; Faiz, M.A.; Abela-Ridder, B.; Ainsworth, S.; Bulfone, T.C.; Nickerson, A.D.; Habib, A.G.; Junghanss, T.; Fan, H.W.; Turner, M.; et al. Strategy for a globally coordinated response to a priority neglected tropical disease: Snakebite envenoming. PLoS Negl. Trop. Dis. 2019, 13, e0007059. [CrossRef]

8. Hunter, C.J.; Piechazek, K.-H.; Nyarang'o, P.M.; Rennie, T.W. Snakebite envenoming. Lancet 2019, 393, 129-131. [CrossRef]

9. Shine, R.; Branch, W.R.; Webb, J.K.; Harlow, P.S.; Shine, T.; Keogh, J.S. Ecology of cobras from southern Africa. J. Zool. 2007, 272, 183-193. [CrossRef]

10. Wüster, W.; Crookes, S.; Ineich, I.; Mané, Y.; Pook, C.E.; Trape, J.-F.; Broadley, D.G. The phylogeny of cobras inferred from mitochondrial DNA sequences: Evolution of venom spitting and the phylogeography of the African spitting cobras (Serpentes: Elapidae: Naja nigricollis complex). Mol. Phylogenet. Evol. 2007, 45, 437-453. [CrossRef]

11. World Health Organization. WHO Guidelines for the Production, Control and Regulation of Snake Antivenom Immunoglobulins; WHO: Geneva, Switzerland, 2010; p. 134.

12. Panagides, N.; Jackson, T.N.; Ikonomopoulou, M.P.; Arbuckle, K.; Pretzler, R.; Yang, D.C.; Ali, S.A.; Koludarov, I.; Dobson, J.; Sanker, B.; et al. How the Cobra Got Its Flesh-Eating Venom: Cytotoxicity as a Defensive Innovation and Its Co-Evolution with Hooding, Aposematic Marking, and Spitting. Toxins 2017, 9, 103. [CrossRef]

13. Kandiwa, E.; Mushonga, B.; Samkange, A.; Fabiano, E. Quantitative Characterization of the Hemorrhagic, Necrotic, Coagulation-Altering Properties and Edema-Forming Effects of Zebra Snake (Naja nigricincta nigricincta) Venom. J. Toxicol. 2018, 2018, 1-8. [CrossRef] [PubMed]

14. Tianyi, F.-L.; Dimala, C.A.; Feteh, V.F. Shortcomings in snake bite management in rural Cameroon: A case report. BMC Res. Notes 2017, 10, 196. [CrossRef] [PubMed]

15. Suleman, M.M.; Shahab, S.; Rab, M.A. Snake bite in the Thar Desert. J.-Pak. Med Assoc. 1998, 48, $306-307$. [PubMed]

16. Namibia Standard Treatment Guidelines, 1st ed.; Ministry of Health and Social Services: Windhoek, Namibia, 2011; p. 891.

17. Sintiprungrat, K.; Watcharatanyatip, K.; Senevirathne, W.; Chaisuriya, P.; Chokchaichamnankit, D.; Srisomsap, C.; Ratanabanangkoon, K. A comparative study of venomics of Naja naja from India and Sri Lanka, clinical manifestations and antivenomics of an Indian polyspecific antivenom. J. Proteom. 2016, 132, 131-143. [CrossRef] [PubMed]

18. Harrison, R.A.; Oluoch, G.O.; Ainsworth, S.; Alsolaiss, J.; Bolton, F.; Arias, A.-S.; Gutiérrez, J.-M.; Rowley, P.; Kalya, S.; Ozwara, H.; et al. Preclinical antivenom-efficacy testing reveals potentially disturbing deficiencies of snakebite treatment capability in East Africa. PLoS Negl. Trop. Dis. 2017, 11, e0005969. [CrossRef] 
19. Tilbury, C.R. Observations on the bite of the Mozambique spitting cobra (Naja mossambica mossambica). S. Afr. Med. J. 1982, 61, 308-313.

20. Laustsen, A.H.; Lomonte, B.; Lohse, B.; Fernandez, J.; Gutiérrez, J.M. Unveiling the nature of black mamba (Dendroaspis polylepis) venom through venomics and antivenom immunoprofiling: Identification of key toxin targets for antivenom development. J. Proteom. 2015, 119, 126-142. [CrossRef]

21. Pantanowitz, L.L. Development of antivenoms in South Africa. S. Afr. J. Sci. 1998, 94, 464-469.

22. Tasoulis, T.; Isbister, G.K. A Review and Database of Snake Venom Proteomes. Toxins 2017, 9, 290. [CrossRef]

23. Petras, D.; Sanz, L.; Segura, A.; Herrera, M.; Villalta, M.; Solano, D.; Vargas, M.; León, G.; Warrell, D.A.; Theakston, R.D.G.; et al. Snake Venomics of African Spitting Cobras: Toxin Composition and Assessment of Congeneric Cross-Reactivity of the Pan-African EchiTAb-Plus-ICP Antivenom by Antivenomics and Neutralization Approaches. J. Proteome Res. 2011, 10, 1266-1280. [CrossRef]

24. Huang, M.Z.; Gopalakrishnakone, P.; Kini, R.M.; Chung, M.C. Complete Amino Acid Sequence of an Acidic, Cardiotoxic Phospholipase A2 from the Venom of Ophiophagus Hannah (King Cobra): A Novel Cobra Venom Enzyme with "Pancreatic Loop". Arch. Biochem. Biophys. 1997, 338, 150-156. [CrossRef] [PubMed]

25. Burke, J.E.; Dennis, E.A. Phospholipase A2 structure/function, mechanism, and signaling1. J. Lipid Res. 2008, 50, S237-S242. [CrossRef] [PubMed]

26. Kini, R.M.; Doley, R. Structure, function and evolution of three-finger toxins: Mini proteins with multiple targets. Toxicon 2010, 56, 855-867. [CrossRef] [PubMed]

27. Girish, V.M.; Kumar, S.; Joseph, L.; Jobichen, C.; Kini, R.M.; Sivaraman, J. Identification and Structural Characterization of a New Three-Finger Toxin Hemachatoxin from Hemachatus haemachatus Venom. PLoS ONE 2012, 7, e48112. [CrossRef] [PubMed]

28. Munawar, A.; Trusch, M.; Georgieva, D.; Hildebrand, D.; Kwiatkowski, M.; Behnken, H.; Harder, S.; Arni, R.; Spencer, P.J.; Schluter, H.; et al. Elapid Snake Venom Analyses Show the Specificity of the Peptide Composition at the Level of Genera Naja and Notechis. Toxins 2014, 6, 850-868. [CrossRef]

29. Mackessy, S.P. Handbook of Venoms and Toxins of Reptiles; CRC Press/Taylor \& Francis Group: Boca Raton, FL, USA, 2016; Available online: https://owlcation.com/stem/Snake-Venom-Composition (accessed on 7 August 2019).

30. Mayr, C. Evolution and Biological Roles of Alternative 3'UTRs. Trends Cell Biol. 2016, 26, 227-237. [CrossRef]

31. Takeda, S.; Takeya, H.; Iwanaga, S. Snake venom metalloproteinases: Structure, function and relevance to the mammalian ADAM/ADAMTS family proteins. Biochim. Biophys. Acta (BBA) Proteins Proteom. 2012, 1824, 164-176. [CrossRef]

32. Aird, S.D.; Watanabe, Y.; Villar-Briones, A.; Roy, M.C.; Terada, K.; Mikheyev, A.S. Quantitative highthroughput profiling of snake venom gland transcriptomes and proteomes (Ovophis okinavensis and Protobothrops flavoviridis). BMC Genom. 2013, 14, 790. [CrossRef]

33. Lahiani, A.; Yavin, E.; Lazarovici, P. The Molecular Basis of Toxins' Interactions with Intracellular Signaling via Discrete Portals. Toxins 2017, 9, 107. [CrossRef]

34. Tan, K.K.; Bay, B.H.; Gopalakrishnakone, P. L-amino acid oxidase from snake venom and its anticancer potential. Toxicon 2018, 144, 7-13. [CrossRef]

35. Yamazaki, Y.; Brown, R.L.; Morita, T. Purification and Cloning of Toxins from Elapid Venoms that Target Cyclic Nucleotide-Gated Ion Channels. Biochemistry 2002, 41, 11331-11337. [CrossRef] [PubMed]

36. Yamazaki, Y.; Morita, T. Structure and function of snake venom cysteine-rich secretory proteins. Toxicon 2004, 44, 227-231. [CrossRef] [PubMed]

37. Adade, C.M.; Carvalho, A.L.O.; Tomaz, M.A.; Costa, T.F.R.; Godinho, J.L.; Melo, P.A.; Lima, A.P.C.A.; Rodrigues, J.C.F.; Zingali, R.B.; Souto-Padrón, T. Crovirin, a Snake Venom Cysteine-Rich Secretory Protein (CRISP) with Promising Activity against Trypanosomes and Leishmania. PLoS Negl. Trop. Dis. 2014, 8, e3252. [CrossRef] [PubMed]

38. Schweitz, H.; Vigne, P.; Moinier, D.; Frelin, C.; Lazdunski, M. A new member of the natriuretic peptide family is present in the venom of the green mamba (Dendroaspis angusticeps). J. Biol. Chem. 1992, 267, 13928-13932.

39. Chen, H.H.; Lainchbury, J.G.; Burnett, J.C. Natriuretic peptide receptors and neutral endopeptidase in mediating the renal actions of a new therapeutic synthetic natriuretic peptide dendroaspis natriuretic peptide. J. Am. Coll. Cardiol. 2002, 40, 1186-1191. [CrossRef]

40. Chen, H.-S.; Rejtar, T.; Andreev, V.; Moskovets, A.E.; Karger, B.L. Enhanced Characterization of Complex Proteomic Samples Using LC-MALDI MS/MS: Exclusion of Redundant Peptides from MS/MS Analysis in Replicate Runs. Anal. Chem. 2005, 77, 7816-7825. [CrossRef] 
41. Liu, H.; Sadygov, R.G.; Yates, I.J.R. A Model for Random Sampling and Estimation of Relative Protein Abundance in Shotgun Proteomics. Anal. Chem. 2004, 76, 4193-4201. [CrossRef]

42. Ainsworth, S.; Petras, D.; Engmark, M.; Süssmuth, R.D.; Whiteley, G.; Albulescu, L.-O.; Kazandjian, T.D.; Wagstaff, S.; Rowley, P.; Wüster, W.; et al. The medical threat of mamba envenoming in sub-Saharan Africa revealed by genus-wide analysis of venom composition, toxicity and antivenomics profiling of available antivenoms. J. Proteom. 2018, 172, 173-189. [CrossRef]

43. Saaiman, E.L.; Buys, P.J.C. Spitting cobra (Naja nigricincta nigricincta) bites complicated by rhabdomyolysis, possible intravascular haemolysis, and coagulopathy. S. Afr. Med. J. 2019, 109, 736-740. [CrossRef]

44. O'Connell, K.L.; Stults, J.T. Identification of mouse liver proteins on two-dimensional electrophoresis gels by matrix-assisted laser desorption/ionization mass spectrometry of in situ enzymatic digests. Electrophoresis 1997, 18, 349-359. [CrossRef]

45. Shevchenko, A.; Wilm, M.; Vorm, O.; Mann, M. Mass Spectrometric Sequencing of Proteins from Silver-Stained Polyacrylamide Gels. Anal. Chem. 1996, 68, 850-858. [CrossRef] [PubMed]

46. Shevchenko, A.; Tomas, H.; Havli, J.; Olsen, J.V.; Mann, M. In-gel digestion for mass spectrometric characterization of proteins and proteomes. Nat. Protoc. 2006, 1, 2856-2860. [CrossRef] [PubMed]

47. Perez-Riverol, Y.; Csordas, A.; Bai, J.; Llinares, M.B.; Hewapathirana, S.; Kundu, D.J.; Inuganti, A.; Griss, J.; Mayer, G.; Eisenacher, M.; et al. The PRIDE database and related tools and resources in 2019: Improving support for quantification data. Nucleic Acids Res. 2018, 47, D442-D450. [CrossRef] [PubMed]

(C) 2020 by the authors. Licensee MDPI, Basel, Switzerland. This article is an open access article distributed under the terms and conditions of the Creative Commons Attribution (CC BY) license (http://creativecommons.org/licenses/by/4.0/). 